\title{
Erratum
}

Journal of Microbiology (2021) Vol. 59, No. 4, pp. 417-425

DOI 10.1007/s12275-021-0573-2

\section{Effects of multi-species probiotic supplementation on alcohol metabolism in rats}

\author{
Tae-Joong Lim, Sanghyun Lim, Jong Hyun Yoon, and Myung Jun Chung*
}

R\&D Center, Cell Biotech, Co., Ltd., 50, Aegibong-ro 409 beon-gil, Gaegok-ri, Wolgot-myeon, Gimpo-si 10003, Republic of Korea

In the article by Lim et al. published in Journal of Microbiology 2021; 59, 417-425, did not include acknowledgments or conflict of interest.

The acknowledgments and conflicts of interest for this article can be found below:

\section{Acknowledgments}

This work was financially supported in part by Cell Biotech Co., Ltd., Republic of Korea.

\section{Conflict of Interest}

We have no conflicts of interest to report.

We apologize for any inconvenience that this may have caused. 